\title{
Airway Dimensions in Asthma and COPD in High Resolution Computed Tomography: Can We See the Difference?
}

\author{
Justyna Kosciuch MD PhD, Rafal Krenke MD PhD, Katarzyna Gorska MD PhD, \\ Malgorzata Zukowska MD PhD, Marta Maskey-Warzechowska MD PhD, \\ and Ryszarda Chazan MD PhD
}

\begin{abstract}
BACKGROUND: Airway remodeling in asthma and COPD results in bronchial wall thickening. The thickness of the bronchial wall can be measured in high-resolution computed tomography. The objectives of the study were to assess the bronchial lumen and wall dimensions in asthma and COPD patients, in relation to disease severity, and to compare the airway dimensions in patients with asthma and COPD. METHODS: Ten asthma subjects and 12 COPD subjects with stable, mild to moderate disease were investigated. All subjects underwent chest high-resolution computed tomography (window level - 450 Hounsfield units, window width 1,500 Hounsfield units). Cross-sections of bronchi (external diameter 1.0-5.0 mm) were identified on enlarged images. The following variables were measured: external and internal diameter, wall area, lumen area, total airway area, the percentage of airway wall area, wall thickness, and the ratio of wall thickness to external diameter. Separate sub-analyses were performed for airways with external diameter $\leq \mathbf{2 . 0} \mathbf{~ m m}$ and external diameter $>2.0 \mathrm{~mm}$. RESULTS: We measured 261 and 348 cross-sections of small airways in subjects with asthma and COPD, respectively. There was a significant difference in wall thickness and wall area, which were both greater in asthmatics than in COPD patients. In bronchi with external diameter $>\mathbf{2 . 0} \mathbf{m m}$, all measured parameters were significantly higher in asthma than COPD. In individual asthmatics the airway wall thickness was similar in all the assessed bronchi, while in COPD it was related to the external airway diameter. CONCLUSIONS: Our results indicate that bronchial walls are thicker in asthmatics than in patients with COPD. It seems that airway wall thickness and the lumen diameter in patients with asthma are related to disease severity. There is no such a relationship in COPD patients. High-resolution computed tomography may be a useful tool in the assessment of airway structure in obstructive lung disease. Key words: asthma; COPD; airway thickness; airway remodeling; high-resolution computed tomography. [Respir Care 2013;58(8):1335-1342. (C) 2013 Daedalus Enterprises]
\end{abstract}

\section{Introduction}

Our knowledge of chronic inflammation and airway structural changes in asthma and COPD is mainly based on autopsy and bronchoscopic studies. The introduction of high-resolution computed tomography (HRCT) offered new possibilities in the qualitative and quantitative assess-

\footnotetext{
The authors are affiliated with the Department of Internal Medicine, Pneumonology, and Allergology, Medical University of Warsaw, Warsaw, Poland, with the exception of Dr Zukowska, who is affiliated with the 2nd Department of Clinical Radiology, Medical University of Warsaw, Warsaw, Poland.
}

The authors have disclosed no conflicts of interest. ment of airway (even as small as $1 \mathrm{~mm}$ in internal diameter) and lung tissue remodeling in asthma ${ }^{1,2}$ and COPD. ${ }^{1,3}$ There is evidence for the relationship between airway diameters measured in HRCT and results of other studies quantifying airway structure and function..$^{4-7}$ Moreover, HRCT seems a reliable tool in studying the changes in airway dimensions after nonspecific challenge tests, ${ }^{8,9}$ the

\footnotetext{
Correspondence: Rafal Krenke MD PhD, Department of Internal Medicine, Pneumonology, and Allergology, Medical University of Warsaw, Banacha 1A, 02-097 Warsaw, Poland. E-mail: rkrenke@wum.edu.pl.
}

DOI: $10.4187 /$ respcare. 02175 
effect of bronchodilators, ${ }^{6,10}$ and the consequences of airway remodeling (eg, air trapping). ${ }^{11}$

The objectives of our study were to assess the bronchial lumen and wall dimensions in asthma and COPD patients in relation to the disease severity, and to compare airway dimensions in patients with asthma and COPD.

\section{Methods}

The study was performed in subjects with stable, mild to moderate asthma $(n=10)$ and COPD $(n=12)$. The study protocol was approved by the institutional review board, and all subjects signed an informed consent form.

The diagnosis and severity of asthma and COPD were assessed in accordance with the Global Initiative for Asthma ${ }^{12}$ and the Global Initiative for Chronic Obstructive Lung Disease ${ }^{13}$ guidelines, respectively. Inclusion criteria for asthmatic patients were as follows: symptoms consistent with mild to moderate asthma according to GINA; ${ }^{12}$ spirometric features of airway obstruction, with a positive bronchial reversibility test (salbutamol $400 \mu \mathrm{g}$ ) and postbronchodilator $\mathrm{FEV}_{1} / \mathrm{FVC}>70 \%$; positive result of methacholine challenge test. Diagnosis of COPD was based on: a positive history of smoking (a minimum smoking history of 10 pack-years); and symptoms indicating COPD (productive cough, progressive exertional dyspnea); $\mathrm{FEV}_{1}$ / FVC $<70 \%$ in post-bronchodilator spirometry; and negative bronchial reversibility test.

Since the aim was to compare the radiographic features of airway remodeling in the natural course of the disease, only patients who had not been receiving inhaled corticosteroids for at least 3 months preceding the study onset

\section{QUICK LOOK}

\section{Current knowledge}

Airway remodeling in asthma and COPD results in bronchial wall thickening, which can be measured with highresolution computed tomography, but the clinical utility of this measurement is unclear.

\section{What this paper contributes to our knowledge}

In patients with asthma, airway wall thickness and lumen diameter were related to asthma severity. In patients with COPD there was no relationship between lumen diameter and disease severity. High-resolution computed tomography may be useful for assessing airway structure in obstructive lung disease.

were included. Therefore, only patients with newly recognized asthma were enrolled.

In all subjects, chest radiograph, pre- and post-bronchodilator spirometry (Lungtest 1000, MES, Kraków, Poland), according to the European Respiratory Society statement, ${ }^{14}$ methacholine challenge test, ${ }^{15}$ and lung HRCT were performed. The demographic and clinical data of the asthma and COPD subjects are shown in Table 1 and Table 2.

CT scanning was preceded by inhalation of a short acting $\beta_{2}$ agonist (salbutamol, $400 \mu \mathrm{g}$ via spacer), in order to achieve maximal bronchodilation. Chest CT scans were performed with 16-row CT scanner (LightSpeed 16, GE Healthcare, Madison, Wisconsin) (collimation $1.25 \mathrm{~mm}$, peak $140 \mathrm{kV}$, current $250 \mathrm{~mA}$, matrix size $512 \times 512$ ). Supine, end-inspiratory scans were performed, with no

Table 1. Characteristics of the Study Groups

\begin{tabular}{|c|c|c|c|}
\hline & Asthma & COPD & $P$ \\
\hline Male/female, no. & $4 / 6$ & $7 / 5$ & .60 \\
\hline Age, y & $36(27-47)$ & $58.5(49-64)$ & .002 \\
\hline Body mass index, $\mathrm{kg} / \mathrm{m}^{2}$ & $25.2(23.0-27.7)$ & $25.1(23.2-30.0)$ & .23 \\
\hline Age at symptom onset, y & $8(3-30)$ & $55(43-60.5)$ & $<.001$ \\
\hline Duration of symptoms, y & $17(5-31)$ & $3(1.5-8)$ & .02 \\
\hline Atopy, no. $(\%)$ & $7(70)$ & $2(16)$ & $<.001$ \\
\hline Never-smokers, no. & 6 & 0 & .005 \\
\hline Past smokers, no. & 3 & 5 & .005 \\
\hline Current smokers, no. & 1 & 7 & .005 \\
\hline Pack-years & $0(0-1.5)$ & $37.5(30-45.5)$ & .005 \\
\hline \multicolumn{4}{|l|}{ Disease severity, no. } \\
\hline Mild & 5 & 7 & .80 \\
\hline Moderate & 5 & 5 & .80 \\
\hline Post-bronchodilator $\mathrm{FEV}_{1}, \mathrm{~L}$ & $2.95(2.4-3.7)$ & $2.3(1.6-2.8)$ & .20 \\
\hline Post-bronchodilator $\mathrm{FEV}_{1}, \%$ of predicted & $87(82-95)$ & $74.5(63.5-86)$ & .20 \\
\hline
\end{tabular}

$\overline{\text { Data are median }(\mathrm{IQR})}$ unless otherwise indicated. 
Table 2. Comparative Characteristics of Subjects With Mild Versus Moderate Asthma or COPD

\begin{tabular}{|c|c|c|c|c|c|c|}
\hline & \multicolumn{3}{|c|}{ Asthma } & \multicolumn{3}{|c|}{ COPD } \\
\hline & Mild & Moderate & $P$ & Mild & Moderate & $P$ \\
\hline$n$ & 5 & 5 & $>.99$ & 7 & 5 & .80 \\
\hline Age, y & $37(31-41)$ & $35(27-47)$ & $>.99$ & $62(49-63)$ & $55(53-67)$ & .50 \\
\hline Male/female, no. & $3 / 2$ & $1 / 4$ & .50 & $5 / 2$ & $3 / 2$ & $>.99$ \\
\hline Height, $\mathrm{cm}$ & $182(163-186)$ & $167(162-167)$ & .20 & $169(164-175)$ & $172(160-180)$ & .64 \\
\hline Body weight, $\mathrm{kg}$ & $93(62-96)$ & $68(65-72)$ & .46 & $72(65-94)$ & $73(60-83)$ & .64 \\
\hline Body mass index, $\mathrm{kg} / \mathrm{m}^{2}$ & $26.3(23.3-27.7)$ & $24(23-27.1)$ & .70 & $25.1(24.2-40)$ & $25(21.5-28.4)$ & .64 \\
\hline Age at symptom onset, y & $4(3-30)$ & $12(4-30)$ & .70 & $59(40-60)$ & $51(48-61)$ & .40 \\
\hline Duration of symptoms, y & $17(9-33)$ & $17(5-18)$ & .70 & $3(2.5-7.5)$ & $2(1-6)$ & .50 \\
\hline Atopy, no. (\%) & $4(80)$ & $3(60)$ & $>.99$ & 0 & $1(20)$ & $>.99$ \\
\hline Never-smokers, no. & 3 & 3 & $>.99$ & 0 & 0 & $>.99$ \\
\hline Past smokers, no. & 1 & 2 & .70 & 4 & 1 & .30 \\
\hline Current smokers, no. & 1 & 0 & .70 & 3 & 4 & .30 \\
\hline Pack-years & $0(0-5)$ & $0(0-1)$ & .70 & $35(30-43)$ & $40(33-47)$ & .75 \\
\hline Post-bronchodilator $\mathrm{FEV}_{1}, \%$ predicted & $95(90-99)$ & $83(82-84)$ & .04 & $86(78-87)$ & $64(55-70)$ & .01 \\
\hline
\end{tabular}

Values are median (IQR) unless otherwise indicated.

contrast administration, at 5 selected lung levels: superior margin of the aortic arch; tracheal bifurcation; $1 \mathrm{~cm}$ below the tracheal bifurcation; inferior pulmonary veins; $2 \mathrm{~cm}$ above the dome of the right hemidiaphragm. The CT image data were reconstructed with a high spatial frequency algorithm and analyzed at a window level of -450 Hounsfield units and a window width of 1,500 Hounsfield units. ${ }^{16}$

The CT images were enlarged (magnification 10), and regions of interest were traced manually. The internal diameter $\left(D_{I}\right)$ and external diameter $\left(D_{E}\right)$ were measured by standard software analysis. Then cross-sections of bronchi with $\mathrm{D}_{\mathrm{E}}$ between 1.0 and $5.0 \mathrm{~mm}$ were identified. To select only cross-sections perpendicular to the airway axis, we analyzed only cross-sections for which the ratio of the largest lumen diameter to the largest lumen diameter perpendicular to it was $\leq 1.2 .{ }^{17}$

Airway wall dimensions were measured by a radiologist blinded to the subject's diagnosis, using a validated method described in earlier studies. ${ }^{9,18}$ The interpretation of the CT scans and all the measurements were consulted with a pulmonologist. After the diameter measurements, we calculated:

- Wall thickness (WT). We assumed that the bronchial wall thickness is constant on the cross section: WT $=$ $\left(D_{E}-D_{I}\right) / 2$

- Relative wall thickness (RWT) (expressed as the ratio of $\mathrm{WT}$ and DE): $\mathrm{RWT}=\mathrm{WT} / \mathrm{D}_{\mathrm{E}}$

- Total airway area $\left(\mathrm{A}_{\mathrm{O}}\right): \mathrm{A}_{\mathrm{O}}=\pi\left(\mathrm{D}_{\mathrm{E}} / 2\right)^{2}$

- Lumen area $\left(\mathrm{A}_{\mathrm{L}}\right): \mathrm{A}_{\mathrm{L}}=\pi\left(\mathrm{D}_{\mathrm{I}} / 2\right)^{2}$

- Airway wall area (WA): WA $=\mathrm{A}_{\mathrm{O}}-\mathrm{A}_{\mathrm{L}}$

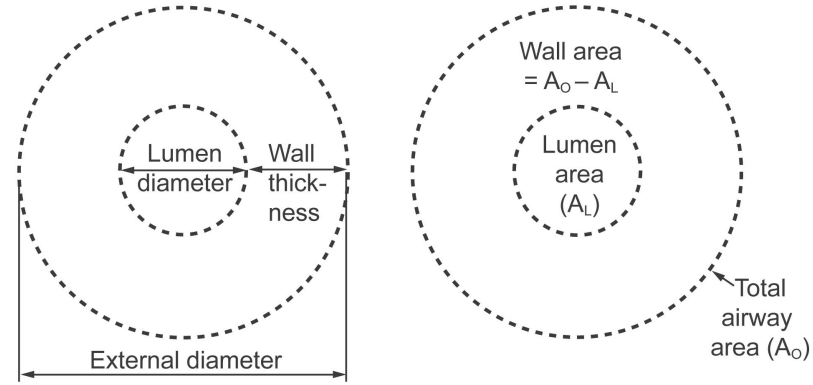

Figure. Airway cross-section measurements. $A_{O}=$ total airway area. $A_{\mathrm{L}}=$ lumen area.

- Relative airway wall area (WA\%) (WA expressed as the percentage of $\left.\mathrm{A}_{\mathrm{O}}\right): \mathrm{WA} \%=\left(\mathrm{WA} / \mathrm{A}_{\mathrm{O}}\right) \times 100$

The measurements are depicted in the Figure.

Two approaches were used to compare the results from the asthmatic versus the COPD subjects. First, the mean values for all parameters were calculated for the individual subject, and then the asthma subjects were compared to the COPD subjects. Second, all the values measured in the asthma subjects were compared to the respective values in COPD subjects. Separate sub-analyses for airways with $\mathrm{D}_{\mathrm{E}} \leq 2.0 \mathrm{~mm}$ versus $>2.0 \mathrm{~mm}$ were performed in both groups, respectively.

All statistical calculations were performed using statistics software (Statistica 6.0, StatSoft, Tulsa, Oklahoma). Data are presented as median and IQR. The MannWhitney U test was applied to compare 2 unrelated samples, while the Spearman rank correlation coefficient was utilized to test potential correlations between different vari- 
Table 3. Airway Dimensions in Mild vs Moderate Asthma

\begin{tabular}{lccr}
\hline \hline & $\begin{array}{c}\text { Mild Asthma } \\
n=119\end{array}$ & $\begin{array}{c}\text { Moderate } \\
\text { Asthma } \\
n=142\end{array}$ & $P$ \\
\hline Lumen diameter, mm & $1.5(1.0-1.9)$ & $1.0(0.8-1.5)$ & $<.001$ \\
Wall thickness, mm & $0.8(0.6-1.0)$ & $0.7(0.5-1.0)$ & .06 \\
Relative wall thickness & $0.27(0.23-0.29)$ & $0.29(0.26-0.31)$ & $<.001$ \\
Total airway area, mm ${ }^{2}$ & $7.5(4.1-11.3)$ & $4.1(2.5-10.2)$ & .002 \\
Lumen area, mm ${ }^{2}$ & $1.8(0.8-2.8)$ & $0.8(0.5-1.8)$ & $<.001$ \\
Wall area, mm & $5.5(3.1-9.1)$ & $3.5(2.0-8.0)$ & .002 \\
Relative wall area, \% & $78(72-83)$ & $82(78-86)$ & $<.001$ \\
& & & \\
\hline Values are median (IQR). & & & \\
\hline
\end{tabular}

ables. $P$ values below .05 were considered statistically significant.

\section{Results}

We identified 261 and 348 bronchial cross-sections eligible for measurements in subjects with asthma and COPD, respectively. The median number of cross-sections evaluated in each subject was $24(20-31)$ in the asthma group and $29(28-30)$ in the COPD group $(P=.17)$. At each of the 5 evaluated lung levels, a mean $5 \pm 2$ bronchi were measured.

\section{Cross-Section Airway Dimensions in Asthma Subjects}

There were no differences in the relative airway wall thickness (expressed as RWT or WA\%) measured at different lung levels. We found significant differences between the airway walls in subjects with mild (5 subjects, 119 assessed airways) versus moderate asthma (5 subjects, 142 assessed airways). WA, $\mathrm{A}_{\mathrm{O}}$, RWT, and WA\% were significantly larger, whereas $\mathrm{D}_{\mathrm{I}}$ and $\mathrm{A}_{\mathrm{L}}$ were significantly smaller in subjects with moderate, compared to mild, asthma (Table 3).

There was no relationship between RWT or WA\% and the duration of asthma symptoms or age. WA\% and RWT for airways with $\mathrm{D}_{\mathrm{E}} \leq 2 \mathrm{~mm}$ and $>2 \mathrm{~mm}$ were similar (Table 4).

\section{Cross-Section Airway Dimensions in COPD Subjects}

There were no differences in RWT and WA\% measured at different lung levels. The airway wall parameters and airway caliber in 7 subjects with mild COPD (207 assessed bronchi) and 5 subjects with moderate COPD (141 assessed bronchi) were comparable.

The walls of smaller airways $\left(D_{E} \leq 2.0 \mathrm{~mm}\right)$ were significantly thicker than the walls of larger bronchi
$\left(D_{E}>2.0 \mathrm{~mm}\right)$ (see Table 4). However, there was no relationship between airway wall parameters $\left(\mathrm{WT} / \mathrm{D}_{\mathrm{E}}\right.$ or WA\%) and the duration of symptoms or subject age. Interestingly, a significant positive correlation was found between the number of pack-years and WA $(r=0.68)$ and WT $(r=0.82)$.

\section{Comparison of Airway Dimensions in Asthma and COPD Subjects}

WT and WA of asthmatic airways were significantly greater than the respective values for the COPD airways. Cross-sections of asthmatic airways were also characterized by higher WA\% and RWT than those found in COPD, but the difference did not reach statistical significance (Table 5). WT, RWT, WA, and WA\% in individual asthma subjects also tended to be higher than in individual COPD subjects, but the differences were not statistically significant (see Table 5).

Parameters defining the airway caliber $\left(D_{E}, A_{O}\right)$ were slightly but not significantly higher in asthma than in COPD. Statistical significance was reached only for the comparison of $\mathrm{A}_{\mathrm{O}}$ measurements in all the bronchi (see Table 5). $A_{L}$ was virtually the same in the asthmatic and COPD airways.

The bronchi with $\mathrm{D}_{\mathrm{E}}>2.0 \mathrm{~mm}$ significantly differed between asthmatic and COPD airways in all the measured parameters. The calculated dimensions were significantly greater in asthmatics when all assessed bronchi were compared (Table 6).

\section{Discussion}

The majority of cross-sectional airway dimensions were greater in asthmatics than in COPD subjects, particularly $\mathrm{A}_{\mathrm{O}}$, WA, and WT. The median values of these parameters were significantly higher in asthmatic than COPD airways when the results of all individual airway measurements were analyzed. $D_{E}$ and $A_{L}$ were also greater in asthmatics than COPD subjects, but the differences were not significant. Since WT and WA do not change during bronchoconstriction, these variables are regarded as more reliable measures of airway thickening than WA\%.17,19 Despite the fact that the WT was greater in asthmatics, the airway lumen was similar in both studied groups when all the bronchi were analyzed. This interesting finding suggests that a larger airway wall thickness is not necessarily associated with a smaller $A_{L}$. This was even more significant when only bronchi with $\mathrm{D}_{\mathrm{E}}>2.0 \mathrm{~mm}$ were compared in both groups. In this segment of airways nearly all airway dimensions were greater in asthmatics than in COPD subjects.

To our knowledge, there have been only a few HRCT studies directly comparing airway dimensions in asthma 
Table 4. Relative Wall Thickness and Relative Wall Area in Airways With Diameter $\leq 2 \mathrm{~mm}$ Versus Airways With Diameter $>2 \mathrm{~mm}$ in Asthma and COPD

\begin{tabular}{|c|c|c|c|c|}
\hline & $\begin{array}{c}\text { Airway } \\
\text { Wall Thickness Variable }\end{array}$ & $\begin{array}{c}\text { Airways With } \\
\text { Diameter } \leq 2 \mathrm{~mm}\end{array}$ & $\begin{array}{c}\text { Airways With } \\
\text { Diameter }>2 \mathrm{~mm}\end{array}$ & $P$ \\
\hline \multirow[t]{2}{*}{ Asthma } & Relative wall thickness, $\mathrm{mm}$ & $0.28(0.26-0.31)$ & $0.28(0.25-0.3)$ & .10 \\
\hline & Relative wall area, $\%$ & $80(78-85)$ & $81(75-84)$ & .10 \\
\hline \multirow[t]{2}{*}{ COPD } & Relative wall thickness, $\mathrm{mm}$ & $0.28(0.25-0.31)$ & $0.27(0.24-0.3)$ & .01 \\
\hline & Relative wall area, $\%$ & $80(75-86)$ & $78(72-85)$ & .01 \\
\hline
\end{tabular}

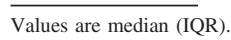

Table 5. Median Airway Dimensions in Subjects With Asthma Versus COPD

\begin{tabular}{|c|c|c|c|c|c|c|}
\hline & $\begin{array}{c}\text { Asthma } \\
\text { Subjects } \\
n=10\end{array}$ & $\begin{array}{c}\text { COPD } \\
\text { Subjects } \\
n=12\end{array}$ & $P$ & $\begin{array}{c}\text { Asthma } \\
\text { Airways } \\
n=261\end{array}$ & $\begin{array}{c}\text { COPD } \\
\text { Airways } \\
n=348\end{array}$ & $P$ \\
\hline External diameter, mm & $3.1(2.3-3.8)$ & $2.7(2.4-3.1)$ & .29 & $2.8(1.9-3.7)$ & $2.5(2.0-3.2)$ & .27 \\
\hline Lumen diameter, mm & $1.4(0.9-1.7)$ & $1.2(1.0-1.4)$ & .53 & $1.2(0.8-1.7)$ & $1.1(0.8-1.5)$ & .11 \\
\hline Wall thickness, mm & $0.78(0.66-1.04)$ & $0.74(0.6-0.8)$ & .33 & $0.75(0.55-1.05)$ & $0.7(0.55-0.85)$ & .005 \\
\hline Relative wall thickness & $0.27(0.26-0.3)$ & $0.27(0.26-0.28)$ & .8 & $0.28(0.25-0.3)$ & $0.27(0.24-0.31)$ & .12 \\
\hline Total airway area, $\mathrm{mm}^{2}$ & $8.0(4.5-11.5)$ & $6.3(4.8-7.7)$ & .35 & $6.1(2.8-10.7)$ & $4.9(3.1-8.0)$ & .02 \\
\hline Lumen area, $\mathrm{mm}^{2}$ & $1.8(0.8-2.3)$ & $1.4(1.0-1.8)$ & .62 & $1.1(0.5-2.3)$ & $0.95(0.5-1.8)$ & .11 \\
\hline Wall area, mm & $5.9(3.6-9.3)$ & $4.8(3.7-5.9)$ & .29 & $4.6(2.3-8.7)$ & $3.9(2.5-6.2)$ & .01 \\
\hline Relative wall area, $\%$ & $78(77-83)$ & $78(76-80)$ & 6 & $81(75-84)$ & $79(73-85)$ & .12 \\
\hline
\end{tabular}

Table 6. Dimensions of Bronchi With External Diameter $>2 \mathrm{~mm}$ in Asthma Versus COPD

\begin{tabular}{|c|c|c|c|c|c|c|}
\hline & $\begin{array}{c}\text { Asthma } \\
\text { Subjects } \\
n=10\end{array}$ & $\begin{array}{c}\text { COPD } \\
\text { Subjects } \\
n=12\end{array}$ & $P$ & $\begin{array}{l}\text { Asthma } \\
\text { Airways } \\
n=183\end{array}$ & $\begin{array}{c}\text { COPD } \\
\text { Airways } \\
n=258\end{array}$ & $P$ \\
\hline External diameter, mm & $3.4(2.9-3.8)$ & $3.0(2.7-3.1)$ & .12 & $3.3(2.7-3.9)$ & $2.8(2.3-3.5)$ & .1 \\
\hline Lumen diameter, mm & $1.5(1.2-1.7)$ & $1.4(1.2-1.6)$ & .62 & $1.5(1.1-1.8)$ & $1.4(1.0-1.6)$ & .008 \\
\hline Wall thickness, mm & $0.9(0.8-1.0)$ & $0.8(0.7-0.8)$ & .06 & $0.9(0.7-1.1)$ & $0.7(0.6-0.9)$ & $<.001$ \\
\hline Relative wall thickness & $0.27(0.26-0.29)$ & $0.27(0.25-0.28)$ & .84 & $0.28(0.25-0.3)$ & $0.27(0.24-0.3)$ & .047 \\
\hline Total airway area, $\mathrm{mm}^{2}$ & $9.8(7.0-11.5)$ & $7.6(5.9-8.1)$ & .07 & $8.5(5.7-11.9)$ & $6.2(4.2-9.6)$ & $<.001$ \\
\hline Lumen area, $\mathrm{mm}^{2}$ & $1.9(1.4-2.3)$ & $1.6(1.2-2.2)$ & .37 & $1.8(0.95-2.5)$ & $1.4(0.78-2.0)$ & .008 \\
\hline Wall area, mm & $7.7(5.5-9.3)$ & $5.5(4.7-6.2)$ & .03 & $6.8(4.4-9.7)$ & $4.9(3.5-7.1)$ & $<.001$ \\
\hline Relative wall area, $\%$ & $79(77-83)$ & $78(74-80)$ & .7 & $81(75-84)$ & $78(72-85)$ & .047 \\
\hline
\end{tabular}

$\overline{\text { Values are median (IQR). }}$

and COPD. Similarly to our findings, Simpson et al observed a larger bronchial wall thickness in subjects with neutrophilic asthma than in subjects with COPD or smoking controls. ${ }^{20}$ Kurashima et al found that airway caliber in asthma was smaller than in COPD. ${ }^{21}$ More studies addressed differences between airway dimensions in subjects with asthma or COPD and healthy controls. Substantial airway thickening in both diseases, as compared to healthy subjects, has been documented. ${ }^{3-5,22}$ Airway wall thickening was observed in mild, moderate, and severe asthma, ${ }^{4,5,18,22,23}$ but also in patients with cough-variant asthma. ${ }^{24}$ Awadh et al found that patients with moderate and severe asthma had greater airway wall thickening than those with mild disease. ${ }^{4}$ It has also been reported that structural changes (airway thickening) in both large and small airways may develop in spite of optimal asthma treatment. ${ }^{23}$ Gupta et al demonstrated that HRCT measures of proximal airway remodeling is associated with impaired lung function. ${ }^{22}$

Several studies showed increased bronchial wall thickness in COPD patients. ${ }^{3,25,26}$ Moreover, airway wall thickening was also found in asymptomatic smokers. ${ }^{25}$ In a 
study by Deveci et al, CT measurement of airway dimensions was found useful for assessment of lung function in patients with COPD, and airway wall thickening was inversely related to the degree of air-flow obstruction. ${ }^{3} \mathrm{Sim}-$ ilar to the significant correlation between number of packyears and WT in our study, a recent study by Donohue et al showed an increase in wall thickness (calculated for an airway with an internal perimeter of $10 \mathrm{~mm}$ ) as a function of the number of pack-years (mean increase $0.002 \mathrm{~mm}$ per 10 pack-years). ${ }^{27}$ The relationship between cigarette smoke exposure and wall thickness (calculated for an airway with internal perimeter of $10 \mathrm{~mm}$ ) has also been reported by Grydeland et al. ${ }^{28}$

Based on the results of previous HRCT studies, a normal range for RWT in healthy subjects is $0.18-0.23 \mathrm{~mm}$, and the normal range for WA\% is $44-70 \% .3,4,17,25$ In our study, RWT and WA\% exceeded these values in both asthmatic and COPD subjects. Thus, albeit we did not have a control group, we suppose that our subjects had an increased airway wall thickness. This is consistent with the results of several other studies. ${ }^{3,4,18,29,30}$

In our previous paper, in which we compared the histopathological differences in the airway structure in asthma and COPD, we found a significantly greater basement membrane thickness in asthmatics. ${ }^{31}$ Other differences, such as muscle layer thickening ${ }^{32}$ and increased number of blood vessels in asthmatic airways, were also reported. ${ }^{33}$ These findings support the hypothesis that airway remodeling results in more pronounced bronchial wall thickening in asthma than in COPD. However, one has to bear in mind that these studies were performed on samples from lobar and segmental bronchi, which are easily accessible by fiberoptic bronchoscopy. Data on histopathological changes in more distal airways are scarce. In our present analysis we found that in COPD subjects, RWT was significantly greater in airways with $\mathrm{D}_{\mathrm{E}}$ of $1.0-2.0 \mathrm{~mm}$ than in larger bronchi. This might partially explain the significant difference between larger airway dimensions and lack of differences between small airway dimensions in asthma and COPD subjects.

Our study showed that airway wall thickness was greater in moderate than in mild asthma. This was associated with a significantly smaller $A_{L}$ in subjects with moderate, as compared to subjects with mild, disease. Similar differences between bronchial wall thickness in subjects with mild versus moderate asthma were reported by Awadh et al. Interestingly, they did not find differences between airway dimensions of subjects with moderate versus severe asthma. ${ }^{4}$ Several other reports have suggested a relationship between asthma severity and airway wall thickness. ${ }^{1,17,18}$ These results are not consistent with histological findings, as airway basement membrane thickening was observed in the initial stages of asthma and did not seem to increase considerably with age or disease severity. ${ }^{34} \mathrm{In}$ our earlier studies, which were designed to evaluate the relationship between HRCT airway dimensions, lung function parameters, and airway inflammatory markers in asthma and COPD, we found a significant correlation between $D_{I}$ and eosinophil count in bronchoalveolar lavage fluid, but no significant correlation between airway dimensions and post-bronchodilator $\mathrm{FEV}_{1} \cdot{ }^{35,36}$ There was, however, a significant negative correlation between $A_{L}$ (particularly when related to body surface area) and airway resistance $\left(r=-0.75\right.$ and $r=-0.92$, respectively). ${ }^{35}$

Some authors have observed a relationship between airway wall thickening and asthma duration. ${ }^{1,17} \mathrm{We}$ found no relationship between airway thickness and duration of symptoms, which is consistent with observations by Little et al. ${ }^{18}$

Contrary to asthma subjects, in COPD subjects we found no correlation between airway wall thickness and disease severity. Similarly, Deveci et al showed the same degree of airway thickening in subjects with moderate and severe COPD. ${ }^{3}$ This can be explained by different mechanisms of airway obstruction in asthma and COPD. In COPD the loss of elastic load seems to play a major role.

We found more pronounced airway wall thickening in the smaller airways $\left(D_{E} \leq 2 \mathrm{~mm}\right)$ in COPD subjects. Airways with $\mathrm{D}_{\mathrm{I}}<2 \mathrm{~mm}$ are the main site of airway obstruction in COPD, and the decline in $\mathrm{FEV}_{1}$ is related to small airway wall thickening ${ }^{37}$ and the loss of elastic load. Such a relationship has not been observed in subjects with asthma. Our results are in agreement with those reported by Deveci et al, who also found a greater wall thickening in the distal airways of COPD subjects and asymptomatic smokers. ${ }^{3}$

We realize some important limitations of our study. A direct comparison of asthma and COPD in the same severity stage may raise doubts, because different criteria are applied for the classification of severity in these diseases (symptoms, $\mathrm{FEV}_{1}$, and peak expiratory flow variability in asthma versus $\mathrm{FEV}_{1}$ only in COPD). Therefore, mild or moderate asthma may not correspond with a similar stage of COPD. Moreover, the comparison of airway dimensions in asthma and COPD could have been biased by the difference in subject age. It should be stressed, however, that albeit our asthmatics were significantly younger than our COPD subjects, they had a much longer duration of the disease. This may be an example of difficulties in appropriate study group matching when comparing asthma and COPD.

Another shortcoming of our study might be the lack of the control group of healthy subjects. This control group was not planned because the study was aimed to compare airway disease in asthma and COPD. However, the inclusion of healthy control subjects would probably have added relevant information to our study, enabling direct compar- 
ison of airway dimension in obstructive airway diseases and healthy controls.

The role of cigarette smoke exposure, not only in COPD patients but also in asthmatics, is yet another controversial point in our study. Cigarette smoke exposure in patients with asthma could potentially affect some measurements. This could be particularly important in comparisons that showed only a trend but not statistical significance. In COPD patients, airway structural changes could have been related to COPD, but also to tobacco smoke exposure. Berger et al showed that some HRCT parameters that reflect airway thickening might be significantly higher in smokers with normal lung function than in healthy nonsmoking controls. ${ }^{38}$ As we have not studied the group of asymptomatic smokers we are not able to differentiate between airway changes related to smoke exposure itself and those associated with COPD. Thus, the interpretation of our results might be somewhat ambiguous.

The number of subjects in each group was relatively small. However, there were more than 200 and 300 individual airways assessed in the asthma and COPD groups, respectively. The main limiting factors affecting sample size was the requirement not to use glucocorticosteroids in the pre-study period and the subject's consent to exposure to radiation during HRCT. The measurements were performed by one radiologist, but consulted with a pulmonologist. In some previous CT studies, airway dimensions were also assessed by one radiologist and a good intra- and inter-observer reproducibility was documented. ${ }^{17}$ The results obtained in studies involving one radiologist ${ }^{17}$ were comparable to those in which 2 specialists participated. $3,4,18,27$

On the other hand, we made efforts to eliminate all the factors that could influence the study results. We applied approved methods and paid special attention to the inclusion criteria. As earlier studies revealed that inhaled corticosteroid therapy significantly decreases basement membrane thickness ${ }^{39}$ and airway airway wall thickness, ${ }^{2}$ the asthma group was limited to those patients who had not been treated with steroids.

\section{Conclusions}

Our results suggest that airway walls in asthma are thicker than in COPD, and this difference is more pronounced in airways with $\mathrm{D}_{\mathrm{E}}>2 \mathrm{~mm}$. It seems that airway wall thickness and the lumen diameter in subjects with asthma are related to the severity of the disease, while this is not the case in COPD patients.

\section{REFERENCES}

1. Harmanci E, Kebapci M, Metintas M, Ozkan R. High-resolution computed tomography findings are correlated with disease severity in asthma. Respiration 2002;69(5):420-426.
2. Capraz F, Kunter E, Cermik H, Ilvan A, Pocan S. The effect of inhaled budesonide and formoterol on bronchial remodeling and HRCT features in young asthmatics. Lung 2007;185(2):89-96.

3. Deveci F, Murat A, Turgut T, Altuntas E, Hamdi Muz M. Airway wall thickness in patients with COPD and healthy current smokers and healthy non-smokers: assessment with high resolution computed tomographic scanning. Respiration 2004;71(6):602-610.

4. Awadh N, Müller NL, Park CS, Abboud RT, FitzGerald JM. Airway wall thickness in patients with near fatal asthma and control groups: assessment with high resolution computed tomographic scanning. Thorax 1998;53(4):248-253.

5. Kasahara K, Shiba K, Okazawa T, Okuda K, Adachi M. Correlation between the bronchial subepithelial layer and whole airway wall thickness in patients with asthma. Thorax 2002;57(3):242-246.

6. Hoshino M, Matsuoka S, Handa H, Miyazawa T, Yaqihashi K. Correlation between airflow limitation and airway dimensions assessed by multidetector CT in asthma. Respir Med 2010;104(6):794-800.

7. Pauls S, Gulkin D, Feuerlein S, Muche R, Kruger S, Schmidt SA et al. Assessment of COPD severity by computed tomography: correlation with lung functional testing. Clin Imaging 2010;34(3): 172-178.

8. Paganin F, Vignola AM, Seneterre E, Bruel JM, Chanez P, Bousquet J. Heterogeneity of airways obstruction in asthmatic patients using high resolution computed tomography. Chest 1995;107(Suppl 3): 145S-146S.

9. Okazawa M, Muller N, McNamara AE, Child S, Verburgt L, Pare PD. Human airway narrowing measured using high resolution computed tomography. Am J Respir Crit Care Med 1996;154(5): 1557-1562.

10. Beigelman-Aubry C, Capderou A, Grenier PA, Straus Ch, Becquemin $\mathrm{MH}$, Similowski T, Zelter M. Mild intermittent asthma: CT assessment of bronchial cross-sectional area and lung attenuation at controlled lung volume. Radiology 2002;223(1):181-187.

11. Kauczor HU, Hast J, Heussel P, Schlegel J, Mildenberger P, Thelen M. Focal air-trapping at expiratory high-resolution CT: comparison with pulmonary function tests. Eur Radiol 2000;10(10):1539-1546.

12. Global Initiative for Asthma (GINA). Global strategy for asthma management and prevention. NHLBI/WHO Workshop Report. Washington DC: National Heart, Lung and Blood Institute, National Institutes of Health, Public Health Service, US Department of Health and Human Services; 2002.

13. Global Initiative for Chronic Obstructive Lung Disease (GOLD). Global strategy for the diagnosis, management and prevention of chronic obstructive pulmonary disease. NHLBI/WHO workshop report. Bethesda: National Heart, Lung and Blood Institute; 2003.

14. Standardized lung function testing. Official statement of the European Respiratory Society. Eur Respir J 1993;16(Suppl):1-100.

15. Crapo RO, Casaburi R, Coates AL, Enright PL, Hankinson JL, Irving CG, et al; American Thoracic Society. Guidelines for methacholine and exercise challenge testing -1999. Am J Respir Crit Care Med 2000;161(1):309-329.

16. McNamara AE, Müller NL, Okazawa M, Arntorp J, Wiggs BR, Paré PD. Airway narrowing in excised canine lungs measured by high-resolution computed tomography. J Appl Physiol 1992;73(1): 307-316.

17. Niimi A, Matsumoto H, Amitani R, Nakano Y, Mishima M, Minakuchi $\mathrm{M}$ et al. Airway wall thickness in asthma assessed by computed tomography. Relation to clinical indices. Am J Respir Crit Care Med 2000;162(4 Pt 1):1518-1523.

18. Little SA, Sproule MW, Cowan MD, Macleod KJ, Robertson M, Love JG et al. High resolution computed tomographic assessment of airway wall thickness in chronic asthma: reproducibility and relationship with lung function and severity. Thorax 2002;57(3): 247-253. 
19. King GG, Müller NL, Pare PD. Evaluation of airways in obstructive pulmonary disease using high-resolution computed tomography. Am J Respir Crit Care Med 1999;159(3):992-1004.

20. Simpson JL, Milne DG, Gibson PG. Neutrophilic asthma has different radiographic features to COPD and smokers. Respir Med 2009; 103(6):881-887.

21. Kurashima K, Hoshi T, Takayanagi N, Takaku Y, Kagiyama N, Ohta $\mathrm{C}$, et al. Airway dimensions and pulmonary function in chronic obstructive pulmonary disease and bronchial asthma. Respirology 2012;17(1):79-86.

22. Gupta S, Siddiqui S, Haldar P, Entwisle JJ, Mewby D, Wardlaw AJ et al. Quantitative analysis of high-resolution computed tomography scans in severe asthma subphenotypes. Thorax 2010;65(9):775-781.

23. Gono H, Fujimoto K, Kawakami S, Kubo K. Evaluation of airway wall thickness and air trapping by HRCT in asymptomatic asthma. Eur Respir J 2003;22(6):965-971.

24. Matsumoto H, Niimi A, Tabuena RP, Takemura M, Ueda T, Yamaguchi $\mathrm{M}$ et al. Airway wall thickening in patients with cough variant asthma and nonasthmatic chronic cough. Chest 2007;131(4):10421049.

25. Nakano Y, Muro S, Sakai H, Hirai T, Chin K, Tsukino M et al. Computed tomographic measurements of airway dimensions and emphysema in smokers. Correlation with lung function. Am J Respir Crit Care Med 2000;162(3 Pt 1):1102-1108.

26. Nakano Y, Wong JC, de Jong PA, Buzatu L, Nagao T, Coxson HO et al. The prediction of small airway dimensions using computed tomography. Am J Respir Crit Care Med 2005;171(2):142-146.

27. Donohue KM, Hoffman EA, Baumhauer H, Guo J, Budoff M, Austin $\mathrm{JH}$ et al. Cigarette smoking and airway wall thickness on CT scan in a multi-ethnic cohort: the MESA Lung Study. Respir Med 2012; 106(12):1655-1664.

28. Grydeland TB, Dirksen A, Coxson HO, Pillai SG, Sharma S, Eide GE et al. Quantitative computed tomography: emphysema and airway wall thickness by sex, age and smoking. Eur Respir J 2009; 34(4):858-865.

29. Saglani S, Papaioannou G, Khoo L, Ujita M, Jeffery PK, Owens C et al. Can HRCT be used as a marker of airway remodeling in children with difficult asthma? Respir Res 2006;7:46-51.
30. Achenbach T, Weinheimer O, Biedermann A, Schmitt S, Freudenstein D, Goutham E et al. MDCT assessment of airway wall thickness in COPD patients using a new method: correlations with pulmonary function tests. Eur Radiol 2008;18(12):2731-2738.

31. Kosciuch J, Krenke R, Gorska K, Baran W, Kujawa M, Hildebrand $\mathrm{K}$, Chazan R. Comparison of airway wall remodeling in asthma and COPD: biopsy findings. Respir Care 2012;57(4):557-564.

32. Dunnill MS, Massarella GR, Anderson JA. A comparison of the quantitative anatomy of the bronchi in normal subjects, in status asthmaticus, in chronic bronchitis, and in emphysema. Thorax 1969; 24(2):176-179.

33. Tanaka H, Yamada G, Saikai T, Hashimoto M, Tanaka S, Suzuki K et al. Increased airway vascularity in newly diagnosed asthma using a high-magnification bronchovideoscope. Am J Respir Crit Care Med 2003;168(12):1495-1499.

34. Payne D, Rogers AV, Adelroth E, Bandi V, Guntupalli KK, Bush A, Jeffery PK. Early thickening of the reticular basement membrane in children with difficult asthma. Am J Respir Crit Care Med 2003; 167(1):78-82.

35. Kosciuch J, Krenke R, Gorska K, Zukowska M, MaskeyWarzechowska M, Chazan R. Relationship between airway wall thickness assessed by high-resolution computed tomography and lung function in patients with asthma and chronic obstructive pulmonary disease. J Physiol Pharmacol 2009;60(Suppl 5):71-76.

36. Górska K, Krenke R, Kosciuch J, Korczynski P, Zukowska M, Domagala-Kulawik J et al. Relationship between airway inflammation and remodeling in patients with asthma and chronic obstructive pulmonary disease. Eur J Med Res 2009;14(Suppl 4):90-96.

37. Hogg JC, Chu F, Utokaparch S, Woods R, Elliott M, Buzatu L et al. The nature of small-airway obstruction in chronic obstructive pulmonary disease. N Engl J Med 2004;350(26):2645-2653.

38. Berger P, Perot V, Desbarats P, Tunon-de-Lara JM, Marthan R, Laurent F. Airway wall thickness in cigarette smokers: quantitative thin-section CT assessment. Radiology 2005;235(3):1055-1064.

39. Jeffery PK, Godfrey RW, Adelroth E, Nelson F, Rogers A, Johansson SA. Effects of treatment on airway inflammation and thickening of basement membrane reticular collagen in asthma. A quantitative light and electron microscopic study. Am Rev Respir Dis 1992;145 (4 Pt 1):890-899. 